\title{
O Acesso à Narrativa: uma leitura de Embassytown, de China Miéville
}

Rui Miguel Mesquita

\section{Resumo}

A partir do romance The City $\mathcal{E}$ the City, China Miéville tem reformulado o gênero que popularizou, o New Weird. Para ilustrar essa reformulação, propomos uma análise de um outro seu romance, Embassytown, no qual é apresentada uma associação perturbadora entre linguagem, imaginação e narrativa, que apura o conceito de aproximação entre literatura e política que Miéville tem perseguido na sua obra.

Palavras-chave: China Miéville; Narrativa; Imaginação. 
1. A publicação em 2009 de The City $\&$ the City, de China Miéville, foi um ponto de viragem dentro da corrente literária que o próprio Miéville havia consolidado no início do século, com a sua trilogia dedicada ao universo ficcional de Bas-Lag (Perdido Street Station, de 2000; The Scar, de 2002; Iron Council, de 2004). The City $\mathcal{E}$ the City introduz nessa corrente, o New Weird, elementos da ficção policial, em particular do roman noir; a densa atmosfera urbana, familiar aos conhecedores deste gênero, à qual não são estranhas uma sugestão de desagregação iminente e até uma certa obnubilação das personagens, reforça manifestamente a consistência dos universos descritos neste romance. Os dois romances seguintes, The Kraken (2010) e Embassytown (2011), continuariam este propósito de integrar gêneros que, à primeira vista, pareceriam muito distantes dos domínios habituais do New Weird: The Kraken pode ser lido como um romance cômico (em particular, como paródia da tendência apocalíptica de alguma ficção científica), enquanto Embassytown assimila livremente elementos do cyberpunk, da literatura fantástica e da ficção política.

Esta combinação não é inteiramente nova na obra de China Miéville: as preocupações políticas do autor já eram patentes na trilogia de Bas-Lag (sobretudo no último romance, Iron Council), haviam sido largamente exploradas na sua tese de doutoramento, Between Equal Rights (2005), e, mais recentemente, motivaram uma revisitação da Revolução de Outubro, October: The Story of the Russian Revolution (2017), na qual Miéville reafirma os ideais marxistas e procede à reavaliação enquanto narrativa dos eventos de 1917. Em rigor, o New Weird foi, desde as suas primeiras formulações na última década do século passado, um gênero propenso ao hibridismo. Pela sua própria condição - o encontro entre a "alta fantasia" (em particular, o seu gosto pelo grotesco e pelas metamorfoses) e a ficção científica (sobretudo na sua vertente mais especulativa) -, o New Weird foi caracterizado como um gênero acretivo por excelência, onde a criação de "mundos secundários" (na formulação de J. R. R. Tolkien) implica uma diversidade de abordagens que expanda significativamente as regras estritas da "alta fantasia". Nas palavras de Jeff VanderMeer: 
New Weird is a type of urban, secondary-world fiction that subverts the romanticized ideas about place found in traditional fantasy, largely by choosing realistic, complex real-world models as the jumping off point for creation of settings that may combine elements of both science fiction and fantasy (VANDERMEER, 2008, p. XVI).

A preferência por ambientes urbanos e por um compromisso com o "mundo real" assume-se assim como a marca distintiva - o fundamento - do New Weird; mas, como também lembra Jeff VanderMeer, a ficção de China Miéville não pode ser descrita tendo em conta apenas estas características.

Na verdade, a ficção de China Miéville introduziu no New Weird, muito por força do seu sucesso comercial e crítico, uma preocupação nova com temas da atualidade; como o próprio Miéville salientou em diversas intervenções públicas após a publicação de Iron Council, a sua obra não pode ser separada de realidades políticas como o movimento alterglobalista ou a contestação à invasão do Iraque - em clara divergência com uma outra tendência dentro do New Weird que procura, antes de tudo, a complexidade e consistência dos seus "mundos secundários", sem um claro compromisso político. Esta divergência quanto às características fundamentais do New Weird levou, por exemplo, a que Miéville tenha expressado as suas dúvidas quanto ao interesse do termo: ele perde a sua acutilância crítica a partir do momento em que funciona menos como um conjunto algo indefinido de características que reúnem uma série de autores que escrevem na fronteira entre "fantasia" e "ficção científica" do que como uma estratégia de marketing editorial destinada a satisfazer um público ávido de leituras semelhantes às dos nomes familiares do gênero (estratégia a que nem o próprio Miéville foi imune; VANDERMEER, 2008, p. XIV). Encontramo-nos assim perante a situação paradoxal de um gênero que, embora seja, na definição do autor, um gênero supremamente crítico, se converteu num instrumento do sistema que supostamente deveria contestar (sobretudo quando usado em processos típicos da distribuição cultural contemporânea: customers who bought this item also bought...).

Neste sentido, o hibridismo dos últimos romances de China Miéville testemunham tanto a sua vinculação ao Nerw Weird como o propósito de transcender as fórmulas fixas do gênero, acrescentando-lhe uma consciência reforçada de que 
esses romances são simultaneamente uma ficção e um produto literário criado num determinado momento sociopolítico. Assim, não só divergem de uma concepção de "nicho" do New Weird, para a qual este é um gênero à parte dentro da ficção científica / alta fantasia (por sua vez, gêneros à parte dentro da literatura, se não mesmo da paraliteratura...), mas também de um determinado entendimento do contexto sociocultural do New Weird que, talvez por um foco excessivo nos problemas causados pela evolução tecnológica, subvaloriza a sua inserção na sociedade e no mercado literário em geral. Ou seja, esses romances inscrevem-se dentro de um conceito alargado, evitando as situações que o mercado editorial instituiu como representativas do New Weird, com o intuito de levantar questões sobre o lugar tanto da literatura como do ser humano dentro da sociedade presente e futura (e de reafirmar, em última análise, a natureza acretiva deste gênero).

Sendo assim, The City $\mathcal{E}$ the City e Embassytown mostram uma maior preocupação com a sua própria relevância dentro do espaço literário e cultural contemporâneo, atenuando o cuidado obsessivo com a elaboração dos "mundos secundários" que é característica do New Weird e das primeiras obras de Miéville. A questão da linguagem e da comunicação ganha uma enorme importância, visto que ambos os romances abordam a questão da inteligibilidade mútua (ou não) entre diferentes comunidades linguísticas; sem esquecer os seus inevitáveis efeitos políticos, os quais, no caso de Embassytown, assumem proporções catastróficas. Há na verdade um terror da incompreensão (bem diferente do horror suscitado por muitas criações típicas do New Weird), visível tanto ao nível diegético, como do próprio discurso, tomado pela incerteza sobre a adequação do "inquérito" ou "relatório" do narrador.

The City $\mathcal{E}$ the City apresenta a situação de duas cidades que coexistem exatamente no mesmo espaço, as quais, no entanto, são percebidas, por força de um poder secreto, como duas cidades diferentes, uma diferença que é reforçada pelo vestuário, pelos costumes, pela arquitetura e - crucialmente pela linguagem. É uma diferença que perturba a estabilidade ontológica de ambas as cidades, à qual se junta a ação do referido poder secreto ("the Breach"), que vigia qualquer tentativa de elucidação entre as duas cidades. A vigilância de um poder supremo sobre as transações linguísticas (e não 
só) entre duas "cidades" será de resto o tema fundamental de Embassytown, o que justifica uma atenção mais demorada.

2. O pretexto inicial de Embassytown parece à primeira vista simples: Avice Benner Cho, viajante transversal do immer (o caminho entre as diferentes galáxias), descreve a recepção anual dos novos embaixadores - os Ambassadors - na cidade de Embassytown, situada no longínquo planeta Arieka. No entanto, essa impressão rapidamente se desfaz, uma vez conhecida qual a função dos Ambassadors: são clones geneticamente manipulados para servir como intérpretes dos habitantes nativos de Arieka, os Hosts. Por outro lado, o fato de terem de ser gerados aos pares chama a atenção para uma característica especial da linguagem dos Hosts: visto que eles têm duas bocas como aparelho fonador, a sua linguagem assume um caráter contrapontístico que a torna incompreensível para os humanos que povoam Arieka. Mais: a linguagem (ou melhor, a Linguagem) dos Hosts é estritamente referencial, sem qualquer vertente semiótica. Por consequência, todas as suas elocuções estão vinculadas à realidade imediata e assumem assim um valor inalterável de verdade - a mentira ou elocuções que não sejam estritamente factuais são inconcebíveis para os Hosts. Como explica Scile, linguista e marido intermitente de Avice, as palavras tomam para os Hosts um sentido liminar; "each is an opening. A door through which the thought of that referent, the thought itself, that reached for that word, can be seen" (MIÉVILLE, 2012, p. 62). Esta concepção transparente da palavra separa os Hosts das restantes espécies em Arieka e cria neles um estranhamento em relação às outras linguagens, inviabilizando uma complexidade superior da comunicação e impondo uma desconfiança mútua que os poderes vigentes tentam minorar através da elaboração de um enquadramento legal tão abrangente quanto possível.

O problema não é apenas linguístico: uma vez conhecido qual o motivo da presença humana no planeta Arieka - os artigos biotécnicos em que os Hosts se especializaram -, é fácil de concluir que Bremen, o poder imperial do planeta Terre, colonizou Arieka e os Hosts, deles extraindo os ditos artigos biotécnicos em troca de um grau superior de desenvolvimento social e político. Aparentemente, esta relação é benéfica para ambas as partes, embora, em conversa com Avice, o 
representante de Bremen, Wyatt, não deixe dúvidas quanto ao motivo final da sua presença em Arieka ("pilfering and cannon-fire"; MIÉVILLE, 2012, p. 130); é um de vários indícios da precária coexistência destas espécies. Outro indício é a própria presença dos Ambassadors, cuja dedicação exclusiva à tradução da Linguagem dos Hosts é frequentemente posta em causa por outro tipo de preocupações, amorosas ou políticas; Avice observa várias vezes como os diferentes Ambassadors manifestam pontos de vista irreconciliáveis sobre os Hosts e a relação que mantêm com eles (na verdade, mesmo a sua posição dentro da comunidade de Embassytown está longe de ser estável, como demonstra Bren, que, depois da morte do seu par Dan, deixa de ser um Ambassador, vindo depois a ser um aliado precioso de Avice).

Não é difícil suspeitar que, nestas circunstâncias, a chegada dos novos Ambassadors precipite a ruptura deste vulnerável entendimento entre os Ariekei e os Terre. Wyatt revelará mais tarde qual foi o propósito da escolha dos novos Ambassadors: tratou-se de uma manobra política por parte de Bremen, com a finalidade de quebrar o poder crescente dos Ambassadors no planeta Arieka e impedir a sua autodeterminação (MIÉVILLE, 2012, p. 271). Com efeito, os novos Ambassadors - EzRa - são, em vez de clones criados em Arieka como os demais Ambassadors, o produto de um treino minucioso em Bremen. Embora o domínio da Linguagem por parte de EzRa seja irrepreensível, os Hosts pressentem todavia uma diferença neles: dotados de uma extraordinária sensibilidade às faculdades próprias dos seres animados (a sua alma, no dizer de Scile; esta sensibilidade fica no entanto largamente por desenvolver ao longo do romance), os Hosts percebem uma dissonância, um leve desencontro por contraste com os outros Ambassadors. "That was the moment everything changed", adverte Avice (MIÉVILLE, 2012, p. 104). Mais tarde, saberemos que os Hosts foram especialmente acicatados pela propensão de EzRa a recapitular as suas palavras; um preciosismo que trai uma concepção divergente da Linguagem.

$\mathrm{Na}$ verdade, o discurso de EzRa assume, contra todas as expectativas dos outros Ambassadors, um caráter encantatório que fascina os Hosts; em breve, eles não poderão deixar de ouvir a Linguagem de EzRa, procurando-a obsessivamente, com um fervor que anteriormente só se verificava em festividades 
como o Festival of Lies, no qual alguns Hosts mais afoitos testam os limites da Linguagem - o seu valor de verdade - e quase proferem "mentiras" (na verdade, aquilo que chamaríamos de contrafatuais). A descrição das técnicas usadas pelos Hosts nas suas quase "mentiras" indica aliás como a Linguagem de EzRa pôde gerar um tal entusiasmo:

There were two main ways the few Ariekei who could lie a little could lie. One was to go slow. They would try to conceive the untrue clause - near-impossible, their minds reacting allergically to such a counterfactual even unspoken, conceived without signification. Having prepared it mentally, however successfully or un-, they would pretendforget it to themselves. Speak each of its constituent words at a certain speed, at a beat, separated, apart enough in the mind of a speaker that each was a distinct concept, utterable with and as its own meaning; but just sufficiently fast and rhythmic that to listeners, they accreted into a ponderous but comprehensible, and untrue, sentence. The liars I had thus far seen with any success were slow-liars.

There was reputed to be another technique. It was the more base and vivid, and by far harder. This was for the speaker to collapse, in their mind, even individual word-meanings, and simply to brute-utter all necessary sounds. To force out a statement. This was quick-lying: the spitting out of a tumble of noises before the untruth of their totality stole a speaker's ability to think them (MIÉVILLE, 2012, p. 149).

Os maneirismos de EzRa como que refinam ambas as técnicas; os Hosts atribuem-lhes um valor exemplar, tanto de segmentação como de súbita concatenação da frase. E o seu exemplo é tão profícuo que um desses Hosts mais afoitos, Beehive, rapidamente se aproxima da faculdade de "mentir", o que gera alarme entre aqueles que pretendem defender a pureza linguística dos Ariekei (a começar por Scile) e a própria comunidade de Embassytown. Beehive acaba por ser assassinado, o que naturalmente põe fim à paz centenária entre os Hosts e o poder político em Embassytown. Um poder político que, por sua vez, atravessa também uma fase de excepcional turbulência; explodem as divergências que estavam desde há muito latentes, e vários Ambassadors, bem como o próprio representante de Bremen, são presos.

Se o convívio de ambas as personalidades já era muito mais difícil do que acontecia com os outros Ambassadors (salientemos que, em cada par, os clones são idênticos uns 
ao outros, exceto na voz que assumem: "cut" ou "turn"), a necessidade avassaladora de, com as suas vozes, tentar aplacar o furor das multidões e a própria consciência de que tinham falhado por completo a sua missão inicial tornam a situação absolutamente insuportável para EzRa: Ez acabará por matar $\mathrm{Ra}$, o que aumenta ainda mais o pânico entre os Ambassadors.

A morte de Ra inaugura uma espiral funesta em Embassytown, a que não escapam Hosts e Ambassadors (e até os próprios materiais de construção, bizarramente animados são na verdade um dos principais artigos biotécnicos criados pelos Hosts -, que caem em ruínas). Repetem-se os suicídios entre os Ambassadors, enquanto um número imenso de Hosts, desesperados por não ouvirem mais a Linguagem em que estavam viciados, comete atos de automutilação: preferem prescindir de toda e qualquer Linguagem a enfrentar um mundo sem as vozes de EzRa. O confronto final entre as multidões de Hosts mutilados (os "Absurdos") e o poder político em Embassytown parece certo, tal como certo é também o colapso de toda a estrutura econômica da colônia; o plano desesperado de alguns Ambassadors - acoplar Ez com um outro Ambassador desirmanado, Cal - só tem sentido como forma de ganhar tempo para uma intervenção militar do poder imperial em Bremen.

Tudo parece caminhar para a aniquilação final, quando surge um desenvolvimento inesperado: alguns Hosts engendram uma forma nova de comunicação que os ajuda a superar a mutilação do seu aparelho fonador (bem como a sua dependência das palavras de EzRa). Essa forma nova passa pelo gesto (numa alusão à teoria gestual da origem da linguagem), ou seja, pela criação de uma deixis que motiva o comentário entusiástico de Avice:

I'd seen them gesticulate. Their commandos or commanders indicating with their giftwings. The Absurd had invented pointing. With the point they'd conceived a that. They'd given the jag of the body, the outthrust limb, power to refer. That that was the key. From it had followed other soundless words.

That. That? No, not that: that.

Each word of Language meant just what it meant. Polysemy or ambiguity were impossible and with them most tropes that made other languages languages at all. But thatness faces every way: it's flexible because it's empty, a universal 
equivalent. That always means and not that other, too. In their lonely silent way, the Absurd had made a semiotic revolution, and a new language" (MIÉVILLE, 2012, p. 344).

Esta nova linguagem é oficializada num apelo que um dos Hosts mais próximos de Beehive, Spanish Dancer, dirige a uma congregação dos seus semelhantes (MIÉVILLE, 2012, p. 39394). Um dos aspectos fundamentais desse apelo é a capacidade narrativa que estes Hosts adquiriram: ele é, antes de tudo, a história da emancipação dos Hosts pela linguagem, ou seja, a sua emancipação é não só o derrube do poder imperial, mas também a transição da Linguagem referencial para a linguagem semiótica. Aliás, há mais um aspecto que permite supor uma outra transição: Spanish Dancer mostra uma preocupação nova com o que Avice designa de metáfora (ou, no dizer de Spanish Dancer, lie that truths ou truthing / lie; MIÉVILLE, 2012, p. 395). A capacidade de pensar e comunicar para além do concreto imediato é um avanço que não poderá ser posto em causa, nem pelo colapso de todo o sistema econômico e legal que Bremen tinha construído, nem pela iminente intervenção militar do poder imperial. A nota final de Embassytown balança entre a descrição do caos deixado pela revolta dos Hosts e a esperança de um futuro digno para a comunidade de Arieka - a esperança que o acesso à significação permite, mesmo que depois esse acesso não seja por si só suficiente para repor um sistema legítimo de governação do planeta.

3. Se entendermos o acesso à linguagem dos Hosts apenas como uma infracção à lei (enquanto materialização de um determinado status quo e efeito de uma remota imposição da vontade do mais forte), então será difícil evitar a leitura de Embassytown como ilustração dos riscos inerentes à linguagem carismática. Com efeito, o surgimento da nova cidade não é acompanhado da criação de um novo enquadramento legal; se frágil é o equilíbrio jurídico entre o poder imperial de Bremen e a sua colônia em Embassytown, não menos fúteis serão afinal os efeitos do discurso de EzRa, dado que a revolta por ele motivada não cria para si uma legitimidade (existe, acima de tudo, como potencialidade). A revolta descrita neste romance afigurarse-ia assim como um ato falhado, um conjunto de "ações e práticas descoordenadas" (LANG JR., 2015, p. 234), a que assiste 
no entanto o dom de expor a fragilidade do direito sideral, bem como da eventual relação simbiótica entre colonizador e colonizado. Haveria assim um vazio sem futuro conhecido, onde tanto caberia uma libertação final como a possibilidade de uma reinscrição das antigas relações de poder ou mesmo de um poder ainda mais abusivo (LANG JR., 2015, p. 235).

No entanto, o final do romance não constitui de forma alguma um lamento pelo "mal menor" que afinal seria a relação entre Bremen e Embassytown. Longe disso, Avice encerra a sua narração num tom de desafio face às represálias e contrariedades que a nova Embassytown pode sofrer por causa da sua rebelião, pelo que é de acreditar que haja alguma espécie de compensação pelo colapso legal que a cidade sofreu - pela sua perda de legitimidade. Talvez possamos definir melhor o que seja essa compensação se recordarmos o discurso de Spanish Dancer à congregação de Hosts no penúltimo capítulo (MIÉVILLE, 2012, p. 393-94): a relação entre Bremen e Embassytown não é descrita enquanto relação jurídica ou econômica, mas sim enquanto relação linguística. $\mathrm{Ou}$ seja, o acesso à linguagem dos Hosts é o acesso à linguagem dos Hosts, sem outras vertentes que se sobreponham à materialidade desta nova forma de comunicação. Os Hosts tomam gradualmente consciência de que a sua existência não pode ser reduzida à posição que ocupam nos enquadramentos jurídicos e econômicos que tenham existido ou possam vir a existir; a linguagem é precisamente uma concretização - talvez a concretização máxima - dessa independência irredutível.

Esta transformação pareceria no entanto demasiado fácil se, ao longo do romance, não se encontrassem diversas alusões aos modos como a linguagem transforma o pensamento e a própria realidade que descreve; a oposição entre a Linguagem dos Hosts e a linguagem a que por fim acedem configura a própria oposição entre a sua inocência primitiva / servidão e a sua possível liberdade. Há assim alguma propriedade essencial na linguagem que não se esgota na mera capacidade de pensamento simbólico e que acaba por ser um elemento necessário da libertação política dos Hosts (inclusive da sua capacidade adquirida para forjarem uma narrativa da sua própria emancipação). Talvez seja útil recordar aqui aquela qualidade que, de acordo com Avice, distingue, no dizer de alguns, quem viaja através das diferentes dimensões do immer: 
"a certain flatness of imagination that keeps the immer from basilisking us out of usefulness. We've learnt its caprices, to travel it, but knowledge can always be learnt" (MIÉVILLE, 2012, p. 37). Imaginação e experiência.

Como se a estrita referencialidade da sua Linguagem os impedisse de compreender plenamente a sua experiência, o acesso dos Hosts à linguagem permite-lhes a projeção das suas referências espaciais e temporais para além do aqui e agora e assim conferir um destino último à sua existência - um destino que, na visão profética de Spanish Dancer, poderão finalmente tomar "nas suas mãos" (em rigor: nas suas asas!). Podemos designar essa projeção de imaginação, pois é como faculdade de recorrer a imagens mentais autónomas, sem necessidade de recorrer aos similes por via dos quais Avice entra em contato com os Hosts, que Spanish Dancer apresenta a linguagem: "You'll be able to say how the city is a pit and a Hill and a standard and an animal that hunts and a vessel on the sea and the sea and how we are fish in it, not like the man who swims weekly with fish but the fish with which he swims, the water, the pool" (MIÉVILLE, 2012, p. 394).

A imaginação pode assim ser entendida como uma extensão do slow-lying. As imagens que ela convoca são separadas e reutilizadas, e é deste modo que elas assumem o seu poder libertador, uma vez que a linguagem (e o pensamento) dos Hosts não precisa mais estar ancorada na referência. A linguagem semiótica dos Hosts é antes de tudo isso; a possibilidade de combinar e evocar pensamentos distantes abre um conjunto de soluções novas de comunicação e de entendimento mútuo. Esta vertente é especialmente importante, pois só ela poderá garantir um futuro digno para a comunidade de Embassytown; a Linguagem dos Hosts condicionava, independentemente das preocupações de Scile sobre a sua pureza linguística, a sua relação com as outras espécies de Arieka, uma relação que oscilava entre a desconfiança ou indiferença e a dependência avassaladora provocada pelas vozes de EzRa. A liberdade combinatória propiciada pela linguagem semiótica permite aos Hosts compreender pela primeira vez a experiência dos outros, e é deste modo que surge no final do romance a possibilidade de uma comunicação profícua entre ambas as partes - sem necessidade da intervenção de um aparelho jurídico (algo que certamente não escapa a um autor de 
vincadas convicções progressistas como Miéville: só é possível haver uma comunicação verdadeira, uma comunicação entre iguais, depois do colapso da "Lei" - vestígio de uma imposição remota da vontade do mais forte). Dir-se-ia: onde há lei, não há comunicação.

Onde há comunicação, talvez não haja lei, mas há decerto uma outra coisa: a narrativa. Com efeito, o apelo final deSpanish Dancer só faz sentido enquanto narrativa da emancipação dos Hosts, história verdadeira dos Ariekei; a possibilidade aberta pela linguagem de rapidamente convocar o passado, o presente e o futuro dos seus semelhantes é naturalmente aproveitada por Spanish Dancer para transmitir um propósito para a existência dos Ariekei. Neste sentido, Spanish Dancer conclui as balbúcies preliminares de Beehive; o seu apelo final é a leal conclusão do Festival of Lies em que o seu parceiro se distinguiu (com consequências fatais). Há assim um fio condutor que vem desde o slow-lying até à faculdade da imaginação, da linguagem semiótica e da narrativa; um fio condutor caracterizado, antes de tudo, pela capacidade de transcender a realidade imediata e aproximar realidades distantes. Não é de surpreender que seja dada no final tanta ênfase à metáfora; como refere Avice,

Their minds were sudden merchants: metaphor, like money, equalised the incommensurable. They could be mythologers now: they'd never had monsters, but now the world was all chimeras, each metaphor a splicing. The city's a heart, I said, and in that a heart and a city were sutured into a third thing, a heartish city, and cities are heart-stained, and hearts are city-stained too. (...) They were in a new world. It was the world we live in (MIÉVILLE, 2012, p. 365-66).

Tendo em conta estas ideias sobre a imaginação, a narrativa, a linguagem e a metáfora, as considerações iniciais acerca da recriação do New Weird que Miéville empreendeu a partir de The City $\mathcal{E}$ the City ganham uma nova vertente: não será a revolta dos Hosts uma rejeição também das fórmulas do New Weird? Nestes termos, a relação entre imaginação, narrativa, linguagem e metáfora é aquela que o New Weird terá perdido: uma excessiva preocupação com a elaboração minuciosa de "mundos secundários" põe em perigo, deste ponto de vista, a sua qualidade ficcional e literária, uma vez que acaba por impedir o jogo da imaginação, isto é, a sua reutilização e livre combinação. Mais: impõe a cosmovisão 
do autor sobre o leitor e cria uma hierarquia de comunicação que, em última análise, é inimiga da literatura. Da mesma forma que os Hosts encontram no final o seu lugar em Arieka, diríamos também que Embassytown encontra por fim o seu espaço: o da literatura como espaço privilegiado de diálogo entre a imaginação, a linguagem e a narrativa, um diálogo que é afinal uma rara ocasião de comunicação entre iguais.

\section{REFERÊNCIAS}

LANG JR., A. F. Between: International Law in The City \& the City and Embassytown. In: EDWARDS, C.; VENEZIA, T. (Eds.) China Miéville: Critical Essays. Canterbury: Gylphi, 2015. p. 213-238.

MIÉVILLE, C. Embassytown. London: Pan, 2012 [2011].

VANDERMEER, J. The New Weird: "It's Alive?". In: VANDERMEER, A.; VANDERMEER, J. (Eds.) The New Weird. San Francisco: Tachyon, 2008. p. ix-xviii. 


\section{Abstract \\ Access to Narrative: Reading China Miéville's Embassytown}

Since his novel The City $\mathcal{E}$ the City, China Miéville has been reshaping the genre which he brought to the literary mainstream, the New Weird. In order to exemplify this reshaping, we propose an analysis of another of his novels, Embassytown, in which is shown a disturbing association between language, imagination and narrative that refines the concept of rapprochement between literature and politics which Miéville has pursued in his oeuvre.

Keywords: China Miéville; Narrative; Imagination. 